\title{
GENDER DIFFERENCES IN SELECTION OF PERMANENT PACEMAKER IMPLANTATION AT MANMOHAN CARDIOTHORACIC VASCULAR AND TRANSPLANT CENTRE, KATHMANDU, NEPAL
}

\author{
Jeevan Khanal, Ratna Raj Poudyal, Surya Devkota, Sanjeev Thapa, \\ Amit Shrestha
}

\begin{abstract}
Background: Permanent pacemaker implantation is a minimally invasive surgical procedure in the management of patients with cardiac rhythm disturbances. Previous studies have reported gender differences in pacemaker selection. There is lack of evidences in selection of pacemaker mode with respect to gender in Nepal. Therefore, this study was performed to compare the frequency of implantation between men and women.
\end{abstract}

Objectives: This study was performed to compare the frequency of implantation rate between men and women.

Methods: The present study is based on all consecutive pacemaker implantations in a single centre between April 2014 and May 2015. A total of 116 patients were categorized into two cohorts according to the type of pacemaker implanted- single chamber or dual chamber. Data were presented as means \pm standard deviation (SD) for continuous variables and as proportions for categorical variables. Comparison of continuous variables between the groups was made with independent Student's t-test. For discrete variables distribution between groups were compared with Chi-square test.

Results: The mean age $( \pm$ SD) of total population at implant was $64.08( \pm 15.09)$ years. Dual chamber units were implanted in $44(37.93 \%)$ of patients, single chamber in $72(62.06 \%)$. Only 14 women (31.81\%) received dual chamber compared with 42 women $(58.33 \%)$ who received single chamber (Chi-square $=18, \mathrm{DF}=1, \mathrm{P}=0.0084$ ). Complete atrioventricular block was the commonest $(56.03 \%)$ indication for permanent pacemaker insertion followed by sick sinus syndrome (33.62\%), symptomatic high-grade AV block (11.20\%). Hypertension (dual chamber $21.55 \%$, single chamber $40.51 \%$ ) was the most common comorbidity in both cohorts.

Conclusions: Women were more likely to receive single chamber systems and less likely to receive dual chamber systems than men.

Keywords: Gender; Permanent pacemaker implantation; Nepal.

\section{Introduction}

Permanent pacemaker implantation is one of the most common therapeutic or prophylactic strategies in the management of patients with cardiac problems at present. ${ }^{1}$ The basic function of the pacemaker is to pace the heart in the absence of intrinsic impulses, and to recognize intrinsic cardiac electrical activity if present and restrain pacing consequently. Optimal selection of the single or dual chamber pacemaker devices depend in terms of arrhythmia, their cost effectiveness and 
longevity. ${ }^{2}$ However, considerable differences have been reported in the frequency of implantation of pacemakers and in the system selected. ${ }^{3,4}$ Gender differences are increasingly recognized in medicine and especially in cardiology. From previous studies, it is known, for example, that women have a higher likelihood for complications and a higher mortality related to coronary revascularization procedures. In arrhythmias, gender-specific variations in the electrophysiological structure of the heart or hormonal effects may explain some of the gender differences. ${ }^{4}$

\section{Methods}

This was hospital based, prospective study conducted at Manmohan Cardiothoracic Vascular and Transplant Centre (MCVTC), Department of cardiology, Maharajgunj, Kathmandu between April 2014 and May 2015. A total of 116 patients were categorized into two cohorts according to the type of pacemaker implanted- single chamber or dual chamber. The study site, one of the tertiary level cardiac centre in Nepal, provides advanced cardiac care to the patients from all over the country.

Study participants were the patients attending Out Patients Department (OPD) and emergency of MCVTC and subsequently admitting for permanent pacemaker implantation. Patients who had pre-existing permanent cardiac pacemaker (PM), defibrillator (ICD) or cardiac resynchronization therapy device (CRT) were excluded from the study. All eligible participants during 14 months period were enrolled in the study.

Participants provided written informed consent after detailed explanation of research purpose and assurance of maintaining privacy and confidentiality. The institutional review board of institute of medicine assessed the ethical part and approved the study.
At initial visit, patients' detailed history of diseases and co-morbidities were recorded. The common co-morbidities included were left ventricular dysfunction (LVD), hypertension, ${ }^{5}$ diabetes mellitus (DM), ${ }^{6}$ chronic kidney diseases (CKD) ${ }^{7}$ coronary artery diseases (CAD), chronic obstructive pulmonary disease $(\mathrm{COPD})^{8}$ and deep vein thrombosis (DVT). ${ }^{9} \quad$ Likewise, information related to prominent symptoms such as syncope and palpitation, and major indications like complete heart block (CHB), sick sinus syndrome (SSS) and symptomatic high degree Atrioventricular (AV) block were also noted.

Permanent pacemaker implantations were performed in a fluoroscopic $\mathrm{C}$ arm equipped theatre. The implantation team consisted of a consultant who performed the implantation, Doctor of Medicine (DM) resident posted in cardiac catheterization laboratory, a cardiac physiologist who checked the pacemaker parameters, a pacemaker technician to operate the fluoroscope for imaging and a scrub nurse.

After implantation, patients were closely monitored on the ward for 48 hours.

Data were compiled, edited and checked to maintain consistency prior to coding and entering in Epidata V.2.1 and exporting to SPSS V.16.0 for further analysis. For inferential statistics, chi-square and tests were conducted to compare the proportions of categorical and mean of continuous variables respectively. A p value of less than 0.05 was considered statistically significant.

\section{Results}

The baseline characteristics are presented in table 1. The mean (SD) age of total population at implant was $64.08 \pm 15.09$ years. Mean age of patients who received dual chamber pacemaker was $64.92 \pm 13.20$ years, not significantly different from those received single chamber pacemaker $(65.80 \pm 12.81$ years, $\mathrm{P}=0.80)$. During the study period, a 
total of 54 women $(48.27 \%)$ received pacemakers. Overall the mean age of women at pacemaker implantation was not significantly different from the age of men (63.2 years \pm 11.3 vs 65.0 years $\pm 12.4, \mathrm{P}=$ $0.37)$.

Dual chamber units were implanted in 44 $(37.93 \%)$ of patients, single chamber in 72 $(62.06 \%)$. Only 14 women $(12.06 \%)$ received dual chamber compared with 42 women (36.20\%) who received single chamber (Chisquare $=18, \mathrm{DF}=1, \mathrm{P}=0.0084$ ).

Table 1: Baseline characteristics

\begin{tabular}{|c|c|c|c|}
\hline $\begin{array}{l}\text { Characteristics } \\
\text { Total number } \\
(\%)\end{array}$ & $\begin{array}{l}\text { Dual } \\
\text { Chamber } \\
(n=44) \\
(37.93 \%)\end{array}$ & $\begin{array}{l}\text { Single } \\
\text { Chambe } \\
\mathbf{r} \\
(\mathbf{n}=72) \\
(62.06 \% \\
)\end{array}$ & $\begin{array}{l}\text { P- } \\
\text { val } \\
\text { ue }\end{array}$ \\
\hline $\begin{array}{l}\text { Age (mean age: } \\
64.94 \pm 15.78 \\
\text { years ) }\end{array}$ & $\begin{array}{l}64.92 \quad \pm \\
13.20\end{array}$ & $\begin{array}{l}65.80 \quad \pm \\
12.81\end{array}$ & $\begin{array}{l}0.8 \\
0\end{array}$ \\
\hline $\begin{array}{l}\text { Women (mean } \\
\text { age: } \\
63.2 \pm 11.3 \text { years }) 5 \\
6(48.27 \%) \\
\text { Men (mean age: } \\
65.0 \quad \pm \quad 12.4 \\
\text { years) } \\
60(51.72 \%) \\
\end{array}$ & $\begin{array}{l}14(31.81) \\
30(68.18)\end{array}$ & $\begin{array}{l}42 \\
(58.33) \\
30 \\
(41.66)\end{array}$ & $\begin{array}{l}0.0 \\
084 \\
0.5 \\
6\end{array}$ \\
\hline \multicolumn{4}{|l|}{ Comorbidities } \\
\hline $\begin{array}{l}\text { LV Dysfunction } \\
24(20.69 \%)\end{array}$ & $9(20.45)$ & $\begin{array}{l}15 \\
(20.88)\end{array}$ & $\begin{array}{l}0.2 \\
0\end{array}$ \\
\hline $\begin{array}{l}\text { Diabetes mellitus } \\
14(12.06 \%)\end{array}$ & $5(11.36)$ & $9(12.50)$ & $\begin{array}{l}0.5 \\
8 \\
\end{array}$ \\
\hline $\begin{array}{l}\begin{array}{l}\text { Hypertension } 72 \\
(62.06 \%)\end{array} \\
\end{array}$ & $25(56.81)$ & $\begin{array}{l}47(65.27 \\
)\end{array}$ & $\begin{array}{l}0.1 \\
1 \\
\end{array}$ \\
\hline CAD $9(7.75 \%)$ & $4(9.09)$ & $5(6.94)$ & $\begin{array}{l}0.8 \\
7\end{array}$ \\
\hline $\begin{array}{ll}\text { CKD } & 28 \\
(24.13 \%) & \\
\end{array}$ & $11(25.00)$ & $\begin{array}{l}17 \\
(23.61)\end{array}$ & $\begin{array}{l}0.3 \\
6 \\
\end{array}$ \\
\hline COPD $5(4.31 \%)$ & $2(4.54)$ & $3(4.16)$ & $\begin{array}{l}0.0 \\
9\end{array}$ \\
\hline DVT $\quad 2(1.72 \%)$ & $0(0)$ & $2(2.77)$ & $\begin{array}{l}0.5 \\
9\end{array}$ \\
\hline
\end{tabular}

Complete atrioventricular block was the commonest (65 patients; 56.03\%) indication for permanent pacemaker insertion followed by sick sinus syndrome (39 patients; $33.62 \%$ ), symptomatic high-grade AV block (13 patients; $11.20 \%$ ). Hypertension (dual chamber $21.55 \%$, single chamber $40.51 \%$ ) was the most common comorbid condition underlying indications for pacemaker implantation. CKD was the second most common disease prevalent among both cohorts. CKD was present in $9.49 \%$ in dual chamber cohort among the total 116 patients and $14.65 \%$ in single chamber cohort among 116 patients.

Table 2: Univariate analysis of variables determining selection of pacemaker in 116 patients.

\begin{tabular}{|c|c|c|}
\hline Variables & $\begin{array}{c}\text { Dual } \\
\text { Chamber } \\
\text { (0dds ratio, } \\
95 \% \text { CI) } \\
\end{array}$ & $\begin{array}{c}\text { Single } \\
\text { Chamber } \\
\text { (0dds ratio, } \\
\text { 95\% CI) } \\
\end{array}$ \\
\hline Age & $\begin{array}{lll}1.04 & (0.87 & - \\
1.21) & & \\
\end{array}$ & $\begin{array}{c}2 .{ }^{66} \\
(1.71-3.96)\end{array}$ \\
\hline Sex & $\begin{array}{l}0.84 \quad(0.71- \\
0.98) \quad\end{array}$ & $\begin{array}{l}3.593(1.101- \\
11.732)^{*}\end{array}$ \\
\hline \multicolumn{3}{|l|}{ Comorbidities } \\
\hline LV Dysfunction & $\begin{array}{lll}1.20 & (1.13 & - \\
1.29) & & \\
\end{array}$ & $\begin{array}{c}0.89 \\
(1.55-4.76) \\
\end{array}$ \\
\hline Diabetes mellitus & $\begin{array}{lll}1.38 & (1.29 & - \\
1.47) & & \\
\end{array}$ & $\begin{array}{c}0.17 \\
(0.97-1.22) \\
\end{array}$ \\
\hline Hypertension & $\begin{array}{lll}1.54 & (1.35 & - \\
1.75) & & \\
\end{array}$ & $\begin{array}{c}2.64 \\
(1.98-3.12) \\
\end{array}$ \\
\hline CAD & $\begin{array}{l}1.20(1.13- \\
1.29)\end{array}$ & $\begin{array}{c}1.12 \\
(0.93-1.82) \\
\end{array}$ \\
\hline CKD & $\begin{array}{lll}1.11 & (1.03 \quad- \\
1.20) & & \\
\end{array}$ & $\begin{array}{c}3.18 \\
(2.38-5.12) \\
\end{array}$ \\
\hline COPD & $\begin{array}{lll}1.09 & (0.95 & - \\
1.23) & & \\
\end{array}$ & $\begin{array}{c}2.15 \\
(1.98-1.12) \\
\end{array}$ \\
\hline DVT & $\begin{array}{lll}3.85 & (3.57 & - \\
4.16) & & \end{array}$ & $\begin{array}{c}1.26 \\
(1.48-2.12)\end{array}$ \\
\hline \multicolumn{3}{|l|}{ Indications } \\
\hline CHB & $\begin{array}{lll}1.54 & (1.35 & - \\
2.75) & & \end{array}$ & $\begin{array}{c}1.61 \\
(0.98-1.64)\end{array}$ \\
\hline SSS & $\begin{array}{lll}1.09 & (0.95 & - \\
1.23) & & \\
\end{array}$ & $\begin{array}{c}1.57 \\
(0.98-1.42) \\
\end{array}$ \\
\hline $\begin{array}{l}\text { Symptomatic } \\
\text { high degree AV } \\
\text { block }\end{array}$ & $\begin{array}{r}2.36 \\
4.63)\end{array}$ & $\begin{array}{c}1.19 \\
(0.98-1.19)\end{array}$ \\
\hline
\end{tabular}

$* \mathrm{P}$ value $<0.001$ 
Following hypertension and CKD, LV dysfunction was present in $7.75 \%$ of total patients in dual chamber and $12.93 \%$ of total patients in single chamber. Diabetes mellitus was present in $4.31 \%$ in dual chamber and $7.75 \%$ in single chamber. Similarly, CAD was present in $3.44 \%$ in dual chamber and $4.31 \%$ in single chamber. Two $(1.72 \%$ of total 116 patients) out of total five patients with COPD, were in dual chamber and three $(2.58 \%$ of total patients) were in single chamber. DVT was present in two patients in single chamber and none in dual chamber.

Univariate analysis of demographic and clinical variables on selection of permanent pacemaker implantation was performed (Table 2). Women were more likely to receive single chamber systems and less likely to receive dual chamber systems than men (Odds ratio:3.593; 95\% confidence interval:1.101-11.732; $\mathrm{p}<0.001)$.

\section{Discussion}

Our study was undertaken to evaluate influence of gender on selection of permanent pacemaker mode. Analysis of data from 116 patients suggests a sex bias in choice of a pacemaker system. Women were more likely to receive single chamber systems and less likely to receive dual chamber than men. Can these findings be explained by differences in the underlying cardiac disorders or demographic data?

Doctors generally implant single chamber pacemakers in elderly patients rather than dual chamber systems. Several studies of factors influencing cardiovascular interventions showed that sex was no longer a determinant once demographic and clinical variables had been adjusted for. ${ }^{10}$ Our results agree with two retrospective studies in the United States in which women were found to receive a dual chamber system less frequently than men. ${ }^{11}$

The clinical importance of the suggested undertreatment of women with dual chamber pacemakers is not easy to evaluate. Dual chamber pacemakers have been shown to offer haemodynamic advantages over single chamber pacemaker. ${ }^{12}$ Although there is evidence that patients treated by advanced pacing have a better quality of life, it is not known whether this improvement is equal in men and women.

What other reasons could there be for doctors deciding in favour of a single chamber pacemaker in women? Firstly, there are some "soft" indications for implanting pacemakers (class II indications in the American College of Cardiology/American Heart Association guidelines). Doctors are known to behave differently towards men and women as far as both diagnostic and therapeutic strategies are concerned. ${ }^{13}$ Doctors seeing women with "soft" indications may tend to implant single chamber pacemakers whereas they choose dual chamber for men. Some of the "hard" indications may also be being neglected in women.

Women often present their symptoms differently from men. ${ }^{14}$ They are more likely to receive the same treatment as men if they present their symptoms as men do. ${ }^{15}$

Finally, we found some published evidence that women sometimes reject sophisticated care in favour of more simple treatments. They may therefore choose not to have dual chamber systems. ${ }^{16}$

Since the implantation of the first artificial pacemaker in 1958 these devices have become the treatment of choice in bradycardias. ${ }^{17}$ There are two often related reasons for implanting a cardiac pacemaker: to relieve symptoms and to improve survival. Most patients treated with pacemaker implantation are elderly persons with either chronic atrioventricular-block (AVB) or sick sinus syndrome (SSS) ${ }^{18}$ Permanent pacing for complete heart block was the commonest indication in this study $(56.03 \%)$ and it was comparable $(42 \%)$ to that reported from a 
similar population. Untreated complete heart block has a one year and five year mortality of $50 \%$ and $75 \%-90 \%$ respectively; while survival is $70 \%-85 \%$ at five years in those paced. ${ }^{19}$

Sick sinus syndrome was responsible for $33.62 \%$ of patients paced in this report and it was identical to that reported from a similar district general population in UK. Pacing for sick sinus syndrome is based on the association of symptoms with specific dysrrhythmia5; it effectively relieves symptoms of bradycardia and can facilitate more aggressive drug treatment of tachyarrhythmias, ${ }^{20}$ but there is no evidence that pacing asymptomatic patients improves prognosis. $^{21}$

\section{Conclusions}

Women were more likely to receive single chamber systems and less likely to receive dual chamber systems than men. Future prospective studies on larger number of patients are needed to confirm and support our findings.

\section{References}

1. Zoll PM. Resuscitation of the heart in ventricular standstill by external electric stimulation. New England Journal of Medicine. 1952;247:768-771.

2. Jacobzone S. Coping with aging: international challenges. Health Affair. 2000;19:213-225.

3. Tse H, Lau C. Clinical trials for cardiac pacing in bradycardia, The End or the Beginning? Circulation. 2006; 114:3-5.

4. Uslan DZ, Tleyjeh IM, Baddour LM, Friedman PA , Jenkins SM, St Sauver JL, et al. Temporal trends in permanent pacemaker implantation. A Population-based study. American Heart Journal. 2008; 155:896-903.

5. Chobanian AV, Bakris GL, Black HR, et al. The seventh report of the Joint National Committee on Prevention, Detection, Evaluation, and Treatment of High Blood Pressure: The JNC 7 report. Journal of American Medical Association. 2003;289:2560.

6. American Diabetes Association. Standards of medical care in diabetes-2014. Diabetes Care. 2014;33(Suppl.1).

7. Levey AS, Eckardt K, Tsukamota Y, et al. Definition and classification of chronic kidney disease: A position statement from kidney disease: Improving global outcome. Kidney International.2005;67:2089-2100.

8. Qaseem A, Timothy JW, Steven EW, et al. Diagnosis and management of stable chronic obstructive pulmonary disease: A clinical practice guideline update from the American College of Physicians, American College of Chest Physicians, American Thoracic Society, and European Respiratory Society. Annals of Internal Medicine. 2011;155:179-191.

9. Hirsh J, Hoak J. Management of deep vein thrombosis and pulmonary embolism- A statement for healthcare professionals from the council on thrombosis (in Consultation With the Council on Cardiovascular Radiology), American Heart Association. Circulation. 1996;93:2212-2245.

10. Wenger NK, Speroff L, Packard B. Cardiovascular health and disease in women. New England Journal of Medicine. 1993;329:247-56.

11. Lamas GA, Pashos CL, Normand SLT, McNeil B. Permanent pacemaker selections and subsequent survival in elderly Medicare pacemaker recipients. Circulation 1995;91:1063-9.

12. Proctor EE, Lemann RB, Mann DL. Single versus dual chamber sensor-driven pacing: comparison of cardiac outputs. American Heart Journal. 1991;122:728-32.

13. Armitage KE, Schneiderman LJ, Bass RA. Response of physicians to medical complaints in men and women. Journal of American Medical Association. 1979;241:2186-7.

14. Shaw LJ, Miller DD, Romeis JC, Kargl D, Younis LT, Chaitman BR. Gender differences in the noninvasive evaluation and management of patients with suspected coronary artery disease. Annals of Internal Medicine. 1995;120:559-66.

15. Healy B. The Yentl syndrome. New England Journal of Medicine. 1991;325:274-6.

16. Horton HL, Marinchak RA, Rials SJ, Kowey PR. Gender diffences in device therapy for malignant ventricular arrhythmias. Archive of Internal Medicine. 1995;155:234-5.

17. Muller C, Cernin J, Glogar D et al. Survival rate and causes of death in patients with pacemakers: dependence on symptoms leading to pacemaker implantation. European Heart Journal. 1988; 9(9):1003-9.

18. Tveskov C, Skytthe A, Arnsbo P, Vaupel JW, Møller M , Christensen K: Twins with implanted pacemakers: Is there an increased mortality risk for the co-twin? A follow-up study based on the Danish Twin Registry and the Danish Pacemaker Register. Europace. 2005; 7: 598e603. 
19. Alpert MA, Curtis JJ, Sanfelippo JF, et al. Comparative survival after permanent ventricular and dual chamber pacing for patients with chronic high degree atrioventricular block with and without pre-existent congestive heart failure. Journal of American College of Cardiology. 1986;7:925-32.
20. Rasmussen K. Chronic sinus node disease: natural course and indications for pacing. European Heart Journal. 1981;2:455-9.

21. Shaw DB, Holmann RR, Gower JI. Survival in sinoatrial disease (sick sinus syndrome). British Medical Journal. 1980;280:139.

Correspondence Address: Dr. Jeevan Khanal, DM Resident, Department of cardiology, Manmohan cardiothoracic vascular and transplant centre, Kathmandu. Phone no: 9851105798, Mail: khanaljimed@gmail.com 